\title{
Application of Differential Colorimetry To Evaluate Anthocyanin- Flavonol-Flavanol Ternary Copigmentation Interactions in Model Solutions
}

Belén Gordillo, ${ }^{\dagger}$ Francisco J. Rodríguez-Pulido, ${ }^{\dagger}$ M. Lourdes González-Miret, ${ }^{\dagger}$ Natalia Quijada-Morín, ${ }^{\S}$ Julián C. Rivas-Gonzalo, ${ }^{\S}$ Ignacio García-Estévez, ${ }^{\S}$ Francisco J. Heredia, ${ }^{\dagger}$ and M. Teresa Escribano-Bailón*,§

${ }^{\dagger}$ Food Colour and Quality Laboratory, Department of Nutrition and Food Science, Facultad de Farmacia, Universidad de Sevilla, 41012 Sevilla, Spain

${ }^{\S}$ Grupo de Investigación en Polifenoles, Facultad de Farmacia, Universidad de Salamanca, Salamanca, Spain

Supporting Information

ABSTRACT: The combined effect of anthocyanin-flavanol-flavonol ternary interactions on the colorimetric and chemical stability of malvidin-3-glucoside has been studied. Model solutions with fixed malvidin-3-glucoside/(+)-catechin ratio (MC) and variable quercetin-3- $\beta$-D-glucoside concentration $(\mathrm{MC}+\mathrm{Q})$ and solutions with fixed malvidin-3-glucoside/quercetin-3- $\beta$-Dglucoside ratio $(\mathrm{MQ})$ and variable $(+)$-catechin concentration $(\mathrm{MQ}+\mathrm{C})$ were tested at levels closer to those existing in wines. Color variations during storage were evaluated by differential colorimetry. Changes in the anthocyanin concentration were monitored by HPLC-DAD. CIELAB color-difference formulas were demonstrated to be of practical interest to assess the stronger and more stable interaction of quercetin-3- $\beta$-D-glucoside with MC binary mixture than (+)-catechin with MQ mixture. The results imply that $\mathrm{MC}+\mathrm{Q}$ ternary solutions kept their intensity and bluish tonalities for a longer time in comparison to $\mathrm{MQ}+\mathrm{C}$ solutions. The stability of malvidin-3-glucoside improves when the concentration of quercetin-3- $\beta$-D-glucoside increases in $\mathrm{MC}+\mathrm{Q}$ mixtures, whereas the addition of $(+)$-catechin in $\mathrm{MQ}+\mathrm{C}$ mixtures resulted in an opposite effect.

KEYWORDS: ternary copigmentation, malvidin-3-glucoside, (+)-catechin, quercetin-3- $\beta$-D-glucoside, differential colorimetry

\section{INTRODUCTION}

Anthocyanins, flavanols, and flavonols are grape flavonoids of special interest in enology due to their influence on important sensory properties of red wines such as color, bitterness, astringency, and stability. Whereas anthocyanins and their derivatives are the pigments directly responsible for the red color, flavanols and flavonols have been shown to contribute to astringency and bitterness. ${ }^{1}$ Also, by combining with anthocyanins, colorless flavonoids are involved in the long-term color stability through copigmentation interactions. ${ }^{2,3}$ In nature, anthocyanins are frequently found participating in noncovalent associations with other colorless substances (the so-called copigments) when they coexist in an aqueous medium such as red wine. This weak association is termed intermolecular copigmentation and represents one of the most complex and efficient mechanisms of anthocyanin chromophore stabilization. ${ }^{4,5}$ The basic role of copigments is to protect the colored flavylium cation against the nucleophilic attack of water, peroxide, and sulfur dioxide bleaching and $\mathrm{pH}$ changes, thus preventing the formation of the colorless hemiacetal and chalcone forms. Furthermore, this interaction could be an initial step leading to the formation of anthocyanin-derived pigments, which better preserve the wine color. ${ }^{6,7}$ Among red wine components, phenolics derived from seeds (mainly flavanols) and skins (mainly flavonols and flavanols) appear to be the most abundant compounds to act as anthocyanin copigments. ${ }^{8}$ As a consequence, the proportions of these compounds are frequently modulated by applying vinification techniques to ensure more stable color formation. $^{9-11}$

Given the importance of grape flavonoids on wine color, the effectiveness of flavanols and flavonols as copigments has been widely studied in model solutions, and the color stabilization that they induce has been extensively demonstrated. ${ }^{12}$ However, most studies focused on copigmentation have considered individual compounds at concentrations and ratios generally much greater than those found in red wines, which makes it difficult to extrapolate the results. Most of these studies stated that individual flavonoids (either flavanols or flavonols) cause more intense and stable color of anthocyanins than the pigments alone, when tested isolated (binary pigment-copigment mixtures). ${ }^{13-16}$ However, controversial or even opposite effects have been recently described when the same phenolic copigments were studied in conjunction. For example, Rustioni et al. $^{17}$ reported that certain combinations of flavonoids extracted from different grape tissues demonstrated a strong copigmentation effect, whereas others surprisingly produced a decrease in the anthocyanin color solution. These findings suggest a possible "anti-copigmentation" effect between

Special Issue: 27th ICP and 8th Tannin Conference (Nagoya 2014)

Received: January 14, 2015

Revised: March 29, 2015

Accepted: March 30, 2015 
colorless flavonoids and anthocyanins when these compounds coexist together in a complex food matrix such as red wines.

In red wine, copigmentation occurs in a "multiple" way, and more than one copigment can interact simultaneously with anthocyanins. Under these conditions, it is expected that there will be competition between the copigments and pigments in the same solution. ${ }^{4}$ The preference or order for these associations could result in positive or negative synergies on the color and color stability, as has been previously reported for other important properties of phenolic compounds such as antioxidant activity. ${ }^{18-20}$

Studies focused on the mechanism of these multiple interactions in model solutions and its effects on copigmentation are scarce, $^{21,22}$ and some aspects are still not well understood such as the possible additive, synergistic, or antagonistic effects among the components present in multiple mixtures and the way to quantify the extent of the process.

From a sensory point of view, the objective assessment of copigmentation seems to be critical for understanding the relationship between grape composition and color in young red wines. ${ }^{21}$ It is assumed that positive effects of copigmentation include greater color stability and also quantitative and qualitative color changes. Therefore, an adequate description of the color variations caused by copigmentation requires considering the changes produced in the entire visible spectral curve (380$770 \mathrm{~nm}$ ), and not only in its visible $\lambda_{\max }$ portion. The color characterization of the multiple copigmentation process in the CIELAB color space by differential colorimetry provides the opportunity of assessing this phenomenon in a global way by considering the modifications in the whole visible spectrum, and conclusions related to the later color stability could be extracted. Research into the industrial evaluation of color variations based on differential colorimetry has shown significant progress in recent years. ${ }^{23-25}$ The CIELAB color attributes lightness, chroma, and hue, and their related color-difference formulas are widely used for industrial applications that require accurate measurement of color changes related to perception and acceptability. Nonetheless, there is very little previous information about the application of differential colorimetry into the study of copigmentation. ${ }^{14,26}$ Recently, differential colorimetry has led to a new point of view in the knowledge of the chemistry of the anthocyanin color and to the interpretation of the copigmentation effects on its visual assessment, both in model solutions and in wines. ${ }^{9,15,22,27}$

Thus, with the aim to further the knowledge of the copigmentation interactions and their implication in the chemical and colorimetric stability of the color of red wine anthocyanins, we have studied the combined effect of anthocyanin-flavanol-flavonol ternary mixtures by differential colorimetry. The levels of flavanols and flavonols in the multiple mixtures were modified to simulate the effect of applying such enological procedures as adding white skins (flavonols) or seeds (flavanols) during the vinification of red wines. The pigment considered in this study represents the main anthocyanin of red grapes and wines (malvidin-3glucoside). The copigment $(+)$-catechin was selected as it is one of the main monomeric flavanols present in grape seed, and quercetin-3- $\beta$-D-glucoside was representative of flavonols present in grape skin.

\section{MATERIALS AND METHODS}

Chemicals and Standards. Malvidin-3-glucoside ( $\geq 97 \%)$ was purchased from Extrasynthese (Genay, France). The copigments $(+)$-catechin $(\geq 96 \%)$ and quercetin-3- $\beta$-D-glucoside $(\geq 90 \%)$ were purchased from Sigma-Aldrich (Madrid, Spain). All chromatographic solvents (acetonitrile and formic acid) were of HPLC grade (Merck, Darmstadt, Germany). Purified water was obtained from a NANOpure Diamond system (Barnsted Inc., Dubuque, IA, USA). All other chemicals (methanol, tartaric acid, and sodium chloride) were of analytical grade and supplied by Panreac Química (Barcelona, Spain).

Preparation of Ternary Copigmented Solutions. All copigmented solutions used were prepared in a wine-like medium containing $5 \mathrm{~g} / \mathrm{L}$ tartaric acid in $12 \%$ ethanol with ionic strength adjusted to $0.2 \mathrm{M}$ by the addition of sodium chloride and $\mathrm{pH}$ adjusted to 3.6 with $\mathrm{NaOH}$.

Two copigmented solutions based on binary combinations of malvidin-3-glucoside with (+)-catechin (MC) and malvidin-3-glucoside with quercetin-3- $\beta$-D-glucoside (MQ) were prepared at the same pigment/copigment concentration (200:200 mg/L). MC and MQ solutions were filtered $(0.45 \mu \mathrm{m}$ Millipore-AP20 filters) and stored closed in darkness at $25{ }^{\circ} \mathrm{C}$ for $2 \mathrm{~h}$ to reach equilibrium. Then, quercetin-3- $\beta$-D-glucoside was added in concentrations 50,100 , and $200 \mathrm{mg} / \mathrm{L}$ to three aliquots of the MC solution to obtain the following ternary mixtures: $\mathrm{MC}+\mathrm{Q} 50, \mathrm{MC}+\mathrm{Q} 100$, and $\mathrm{MC}+\mathrm{Q} 200$. In the same way $(+)$-catechin was added in concentrations of 50,100, and $200 \mathrm{mg} / \mathrm{L}$ to three aliquots of the MQ solution to obtain the following ternary mixtures: $\mathrm{MQ}+\mathrm{C} 50, \mathrm{MQ}+\mathrm{C} 100$, and $\mathrm{MQ}+\mathrm{C} 200$.

All of the copigmented solutions, in both binary and ternary combinations, were prepared in triplicate and stored closed in darkness at $25^{\circ} \mathrm{C}$. The final anthocyanin concentration was the same in all cases $(200 \mathrm{mg} / \mathrm{L})$. Samples $(n=24)$ were taken periodically for the colorimetric and chemical analysis at 2, 24, and $72 \mathrm{~h}$ and at 1,2 , and 3 weeks.

HPLC-DAD Analysis. The content of malvidin-3-glucoside in the model solutions and its evolution over the storage period were evaluated by HPLC-DAD using a Hewlett-Packard 1200 series liquid chromatograph (Palo Alto, CA, USA), equipped with a quaternary pump, column heater, UV-vis diode array detector, automatic injector, and ChemStation software. A Zorbax SB C18 column (4.6 $\mathrm{mm} \times$ $250 \mathrm{~mm}, 4.6 \mu \mathrm{m}$ particle size) thermostated at $38{ }^{\circ} \mathrm{C}$ was used. The solvents used were (A) acetonitrile/formic acid/water (3:10:87) and (B) acetonitrile/formic acid/water (50:10:40). The elution profile was as follows: $0-5 \mathrm{~min}, 94 \% \mathrm{~A} ; 5-7.5 \mathrm{~min}, 70 \% \mathrm{~A} ; 7.5-12.5 \mathrm{~min}, 60 \% \mathrm{~A}$; 12.5-16 min, 55\% A; $16-19$ min, 50\% A; $19-20 \mathrm{~min}, 94 \%$ A. The flow rate was $1 \mathrm{~mL} / \mathrm{min}$, and the injection volume was $50 \mu \mathrm{L}$. UV-vis spectra were recorded from 200 to $800 \mathrm{~nm}$ with a bandwidth of $2.0 \mathrm{~nm}$. The quantification was performed at $525 \mathrm{~nm}$ by HPLC-DAD using calibration curves of malvidin-3-glucoside standard. All analyses were carried out in duplicate, and results were expressed as milligrams per liter.

Analysis of Copigmentation by Colorimetric Measurements. The absorption spectra $(380-770 \mathrm{~nm})$ of all solutions were recorded at constant intervals $(\Delta \lambda=2 \mathrm{~nm})$ with a Hewlett-Packard UV-vis HP8453 spectrophotometer, using $5 \mathrm{~mm}$ path length glass cells and distilled water as a reference. The CIELAB parameters were calculated from the absorption spectra by using the original software CromaLab, ${ }^{28}$ following the recommendations of the Commission International de L'Eclariage: CIE $196410^{\circ}$ Standard Observer and the Standard Illuminant D65, corresponding to natural daylight. ${ }^{29}$ CIELAB parameters were calculated: $L^{*}$ (the correlate of lightness; ranging from 0 , black, to 100 , white) and two color coordinates, $a^{*}$ (which takes positive values for reddish colors and negative values for greenish ones) and $b^{*}$ (positive for yellowish colors and negative for bluish ones). From these coordinates, other color parameters are defined: the hue angle $\left(h_{a b}\right.$, the correlate of chromaticity or tone, and the chroma $C^{*}{ }_{a b}$, the correlate of saturation or intensity of color). Moreover, $L^{*}, C^{*}{ }_{a b}$, and $h_{a b}$ can be distinguished as quantitative or qualitative parameters as they indicate quantitative $\left(L^{*}\right.$ and $\left.C^{*}{ }_{a b}\right)$ or qualitative $\left(h_{a b}\right)$ attributes of color.

The color changes of solutions induced by copigmentation and their color stability over the storage period were evaluated by differential colorimetry according to the methodology described in Gordillo et al., ${ }^{15}$ which is based on the application of various different 
Table 1. Mean Values and Standard Deviations $(n=3)$ of Colorimetric Parameters $\left(L^{*}, a^{*}, b^{*}, C^{*}{ }_{a b}, h_{a b}\right)$ Obtained in MC and MQ Binary Solution and Their Respective Ternary Copigmented Solutions after the Addition of Increasing Concentrations of Quercetin-3- $\beta$-O-glucoside to MC and (+)-Catechin to $\mathrm{MQ}$ at $2 \mathrm{~h}$ and 3 Weeks of Storage $\left(25^{\circ} \mathrm{C}\right)^{a}$

\begin{tabular}{|c|c|c|c|c|c|c|c|c|}
\hline & \multicolumn{4}{|c|}{ MC solutions ${ }^{b}$} & \multicolumn{4}{|c|}{ MQ solutions ${ }^{c}$} \\
\hline & \multirow{2}{*}{$\frac{\text { binary mixture }}{\mathrm{MC}}$} & \multicolumn{3}{|c|}{ multiple mixture } & \multirow{2}{*}{$\frac{\text { binary mixture }}{\text { MQ }}$} & \multicolumn{3}{|c|}{ multiple mixture } \\
\hline & & $\mathrm{MC}+\mathrm{Q} 50$ & $\mathrm{MC}+\mathrm{Q} 100$ & $\mathrm{MC}+\mathrm{Q} 200$ & & $\mathrm{MQ}+\mathrm{C} 50$ & $\mathrm{MQ}+\mathrm{C} 100$ & $\mathrm{MQ}+\mathrm{C} 200$ \\
\hline \multicolumn{9}{|c|}{$2 \mathrm{~h}$ of Storage } \\
\hline$L^{*}$ & $73.1 \pm 0.1 \mathrm{a}$ & $71.4 \pm 0.4 b$ & $67.0 \pm 2.6 c$ & $64.3 \pm 0.6 c$ & $65.2 \pm 0.1 \mathrm{a}$ & $65.2 \pm 0.5 a$ & $64.7 \pm 0.1 \mathrm{a}$ & $65.1 \pm 0.4 \mathrm{a}$ \\
\hline$a^{*}$ & $42.5 \pm 0.1 \mathrm{a}$ & $44.0 \pm 0.6 \mathrm{~b}$ & $45.6 \pm 0.8 b$ & $47.2 \pm 0.3 c$ & $47.6 \pm 0.6 a$ & $48.2 \pm 0.6 \mathrm{a}$ & $47.7 \pm 0.3 a$ & $47.9 \pm 0.3 a$ \\
\hline$b^{*}$ & $-4.4^{\circ} \pm 0.1 \mathrm{a}$ & $-6.3^{\circ} \pm 0.5 b$ & $-7.9^{\circ} \pm 1.6 \mathrm{~b}$ & $-11.8^{\circ} \pm 0.6 \mathrm{c}$ & $-11.1^{\circ} \pm 0.1 \mathrm{a}$ & $-11.3^{\circ} \pm 0.1 \mathrm{a}$ & $-11.5^{\circ} \pm 0.1 \mathrm{a}$ & $-12.2^{\circ} \pm 0.1 \mathrm{~b}$ \\
\hline$C^{*}{ }_{a b}$ & $42.7 \pm 0.1 \mathrm{a}$ & $44.5 \pm 0.6 b$ & $46.2 \pm 1.1 \mathrm{~b}$ & $48.6 \pm 0.4 c$ & $48.7 \pm 0.6 a$ & $49.7 \pm 0.6 a$ & $49.1 \pm 0.1 \mathrm{a}$ & $49.5 \pm 0.3 \mathrm{a}$ \\
\hline$h_{a b}$ & $-5.8^{\circ} \pm 0.1 \mathrm{a}$ & $-8.2^{\circ} \pm 0.6 b$ & $-9.3^{\circ} \pm 1.9 \mathrm{~b}$ & $-13.9^{\circ} \pm 0.6 \mathrm{c}$ & $-13.3^{\circ} \pm 0.1 \mathrm{a}$ & $-13.3^{\circ} \pm 0.1 \mathrm{a}$ & $-13.6^{\circ} \pm 0.2 \mathrm{a}$ & $-14.3^{\circ} \pm 0.2 \mathrm{~b}$ \\
\hline total color & $50.1 \pm 0.2 a$ & $52.9 \pm 0.3 b$ & $56.1 \pm 0.7 c$ & $60.3 \pm 0.3 \mathrm{~d}$ & $60.4 \pm 0.3 a$ & $60.1 \pm 1.0 \mathrm{a}$ & $60.3 \pm 0.2 a$ & $60.7 \pm 0.5 a$ \\
\hline \multicolumn{9}{|c|}{3 Weeks of Storage } \\
\hline$L^{*}$ & $81.5 \pm 0.1 \mathrm{a}$ & $72.8 \pm 0.2 b$ & $69.8 \pm 0.4 c$ & $67.3 \pm 0.3 \mathrm{~d}$ & $64.5 \pm 0.5 a$ & $66.4 \pm 0.2 b$ & $66.8 \pm 0.1 b$ & $66.9 \pm 0.2 b$ \\
\hline$a^{*}$ & $32.2 \pm 0.4 \mathrm{a}$ & $36.7 \pm 0.1 b$ & $39.6 \pm 0.5 c$ & $45.4 \pm 0.2 \mathrm{~d}$ & $47.5 \pm 0.1 \mathrm{a}$ & $44.5 \pm 0.3 b$ & $42.0 \pm 0.2 c$ & $41.7 \pm 0.2 c$ \\
\hline$b^{*}$ & $5.6^{\circ} \pm 0.3 \mathrm{a}$ & $2.9^{\circ} \pm 0.1 \mathrm{~b}$ & $1.4^{\circ} \pm 0.1 \mathrm{c}$ & $-2.5^{\circ} \pm 0.1 \mathrm{~d}$ & $-7.5^{\circ} \pm 0.1 \mathrm{a}$ & $-6.8^{\circ} \pm 0.1 \mathrm{~b}$ & $-5.8^{\circ} \pm 0.1 c$ & $-4.5^{\circ} \pm 0.2 \mathrm{~d}$ \\
\hline$C^{*}{ }_{a b}$ & $32.3 \pm 0.3 \mathrm{a}$ & $36.7 \pm 0.1 b$ & $39.6 \pm 0.5 c$ & $45.6 \pm 0.2 \mathrm{~d}$ & $48.1 \pm 0.1 \mathrm{a}$ & $45.4 \pm 0.3 b$ & $42.4 \pm 0.1 c$ & $41.8 \pm 0.2 c$ \\
\hline$h_{a b}$ & $6.6^{\circ} \pm 0.4 \mathrm{a}$ & $2.8^{\circ} \pm 0.4 \mathrm{~b}$ & $1.9^{\circ} \pm 0.2 \mathrm{c}$ & $-3.4^{\circ} \pm 0.1 \mathrm{~d}$ & $-8.9^{\circ} \pm 0.2 \mathrm{a}$ & $-8.8^{\circ} \pm 0.1 \mathrm{a}$ & $-7.3^{\circ} \pm 0.1 \mathrm{~b}$ & $-6.7^{\circ} \pm 0.2 b$ \\
\hline total color & $36.2 \pm 0.4 \mathrm{a}$ & $45.7 \pm 0.1 b$ & $49.8 \pm 0.2 c$ & $56.1 \pm 0.1 \mathrm{~d}$ & $60.2 \pm 0.2 a$ & $55.9 \pm 0.4 b$ & $54.0 \pm 0.2 c$ & $53.3 \pm 0.3 \mathrm{~d}$ \\
\hline
\end{tabular}

${ }^{a}$ Different letters in the same row indicate significant differences $(p<0.05$; Tukey test) between binary and ternary mixtures for each MC and MQ solution, respectively. ${ }^{b} \mathrm{MC}, \mathrm{Mv} 3$-glc/ (+)-cat (200:200 mg/L); MC+Q50, MC+Q100, MC+Q200, MC solution, $+50,+100,+200 \mathrm{mg} / \mathrm{L}$ of querc 3-glc. ${ }^{c} \mathrm{MQ}$ Mv 3-glc/querc 3-glc (200:200 mg/L); MQ+C50, MQ+C100; MQ+C200, MQ solution +50,+100,+200 mg/L of (+)-cat.

color-difference formulas. The color difference between pairs of samples was computed as the Euclidean distance between two points in the three-dimensional CIELAB space by means of the CIE76 color difference formulas: $\Delta E^{*}{ }_{a b}=\left[\left(\Delta L^{*}\right)^{2}+\left(\Delta a^{*}\right)^{2}+\left(\Delta b^{*}\right)^{2}\right]^{1 / 2}$. Also, on the basis of $\Delta E^{*}{ }_{a b}$ the parameter total color was calculated as the color difference between the color of each sample $\left(L^{*}, a^{*}\right.$, and $\left.b^{*}\right)$ and distilled water, which correspond with an achromatic reference $\left(L^{*}=\right.$ $\left.100, a^{*}=0, b^{*}=0\right)$, as follows:

$$
\text { Total color: }\left[\left(L^{*}-100\right)^{2}+\left(a^{*}-0\right)^{2}+\left(b^{*}-0\right)^{2}\right]^{1 / 2}
$$

The trend of the changes in each individual color attribute between pairs of samples was evaluated by means of the absolute lightness, chroma, and hue differences $\left(\Delta L^{*}, \Delta C^{*}{ }_{a b}, \Delta h_{a b}\right)$. Also, the relative contribution of each color attribute that makes a given color difference value $\left(\Delta E^{*}{ }_{a b}\right)$ was calculated as the quadratic differences of lightness, chroma, and hue $\left(\% \Delta^{2} L, \% \Delta^{2} C\right.$, and $\left.\% \Delta^{2} H\right)$, expressed as percentages:

rel contribution (\%) of lightness: $\% \Delta^{2} L=\left[\left(\Delta L^{*}\right)^{2} /\left(\Delta E_{a b}^{*}\right)^{2}\right] \times 100$

rel contribution (\%) of chroma: $\% \Delta^{2} C=\left[\left(\Delta C^{*}{ }_{a b}\right)^{2} /\left(\Delta E_{a b}^{*}\right)^{2}\right] \times 100$

rel contribution (\%) of hue: $\% \Delta^{2} H=\left[(\Delta h)^{2} /\left(\Delta E_{a b}^{*}\right)^{2}\right] \times 100$

$\Delta H$ is mathematically deduced from $\Delta H=\left[\left(\Delta E^{*}{ }_{a b}\right)^{2}-\left((\Delta L)^{2}+\right.\right.$ $\left.\left.(\Delta C)^{2}\right)\right]^{1 / 2}$.

Statistical Analysis. All statistical analyses were performed using Statistica v.8.0 software. $^{30}$ Univariate analysis of variance (Tukey test, $p<0.05$.) was applied to establish statistical differences for the anthocyanin concentration and the colorimetric characteristic between binary and multiple copigmented solutions.

\section{RESULTS AND DISCUSSION}

Effect of Multiple Copigmentation on Color Characteristics by Differential Colorimetry. Table 1 shows the influence of increasing concentrations of quercetin-3- $\beta-O$ glucoside and $(+)$-catechin on the colorimetric parameters $\left(L^{*}, a^{*}, b^{*}, C^{*}{ }_{a b}\right.$, and $\left.h_{a b}\right)$ and total color of MC and MQ solutions, respectively, at $2 \mathrm{~h}$ after their preparation. Results showed that the two copigments studied have quite different abilities to interact with malvidin-3-glucoside in multiple copigmentation conditions. In particular, the addition of quercetin-3- $\beta$-D-glucoside caused an immediate increase in the total color of the MC solutions, which reflects the preferential binding between quercetin-3- $\beta$-D-glucoside and the flavylium ions and the shift of the equilibrium toward the colored forms. The magnitude of this effect, expressed as the relative increases of the Total color, was significantly $(p<0.05)$ correlated with the quercetin-3- $\beta$-D-glucoside concentration. Specifically, the Total color was increased by 5,12 , and $20 \%$ at 50,100 , and $200 \mathrm{mg} / \mathrm{L}$ of quercetin-3- $\beta$-D-glucoside. Thus, quercetin-3- $\beta$-Dglucoside was demonstrated to have a strong affinity for malvidin-3-glucoside in the presence of $(+)$-catechin. Also, the addition of quercetin-3- $\beta$-D-glucoside to MC solutions produced a progressive decrease in lightness and hue values $\left(L^{*}\right.$ and $\left.h_{a b}\right)$, followed by an increase of chroma $\left(C^{*}{ }_{a b}\right)$, which means a gradual and significant intensification of the color.

In contrast, the addition of $(+)$-catechin did not greatly influence the colorimetric characteristics of $\mathrm{MQ}$ solutions at any tested level, with the exception of the $b^{*}$ and hue values, which were significantly $(p<0.05)$ decreased at $200 \mathrm{mg} / \mathrm{L}$. These slight variations observed in the qualitative attributes of color ( $b *$ and hue values) denote a bluish effect. In any case, no statistically significant differences were found in the total color, chroma, and lightness (quantitative attributes) between MC and $\mathrm{MQ}+\mathrm{C}$ solutions, indicating similar color intensity in both binary and ternary mixtures. Thus, in comparison to quercetin3 - $\beta$-D-glucoside, $(+)$-catechin was demonstrated to have a much lower affinity for malvidin-3-glucoside in multiple conditions.

The different abilities of quercetin-3- $\beta$-D-glucoside and $(+)$-catechin to modify the copigmentation equilibrium in multiple conditions can be explained in terms of their specific binding strengths and concentrations resulting in variable effects in color. ${ }^{4}$ With respect to the MQ solutions, our results suggest that the strong interaction initially established between quercetin-3- $\beta$-D-glucoside and malvidin-3-glucoside prevents the subsequent binding with $(+)$-catechin. As expected, quercetin-3$\beta$-D-glucoside offers larger extended $\pi$ conjugation that makes the molecule more planar and facilitates the $\pi-\pi$ interactions to form stable copigmentation complexes, ${ }^{16,31}$ so the availability of the flavylium ion to interact with (+)-catechin could be strongly 
Table 2. Color, Lightness, Chroma, and Hue Differences $\left(\Delta E^{*}{ }_{a b}, \Delta L^{*}, \Delta C^{*}{ }_{a b}, \Delta h_{a b}\right)$ between Binary and Ternary Copigmented Solutions after the Addition of Increasing Concentrations of Quercetin-3- $\beta$ - $O$-glucoside to MC Solutions and (+)-Catechin to MQ Solutions, Calculated as Mean Values at $2 \mathrm{~h}$ and 3 Weeks of Storage $\left(25^{\circ} \mathrm{C}\right)$

\begin{tabular}{|c|c|c|c|c|c|c|}
\hline & \multicolumn{3}{|c|}{ MC solutions ${ }^{a}$} & \multicolumn{3}{|c|}{ MQ solutions ${ }^{b}$} \\
\hline & $\mathrm{MC}+\mathrm{Q} 50 / \mathrm{MC}$ & $\mathrm{MC}+\mathrm{Q} 100 / \mathrm{MC}$ & $\mathrm{MC}+\mathrm{Q} 200 / \mathrm{MC}$ & $\mathrm{MQ}+\mathrm{C} 50 / \mathrm{MQ}$ & $\mathrm{MQ}+\mathrm{C} 100 / \mathrm{MQ}$ & $\mathrm{MQ}+\mathrm{C} 200 / \mathrm{MQ}$ \\
\hline \multicolumn{7}{|c|}{$2 \mathrm{~h}$ of Storage } \\
\hline$\Delta E_{a b}^{*}$ & 2.9 & 7.7 & 12.4 & 0.6 & 1.2 & 1.1 \\
\hline$\Delta L^{*}$ & -1.7 & -6.1 & -8.8 & 0.0 & -0.5 & -0.1 \\
\hline$\Delta C^{*}{ }_{a b}$ & +1.8 & +3.5 & +5.9 & +1.0 & +0.4 & +0.8 \\
\hline$\Delta h_{a b}$ & $-2.4^{\circ}$ & $-3.5^{\circ}$ & $-8.1^{\circ}$ & $0.0^{\circ}$ & $-0.3^{\circ}$ & $-1.0^{\circ}$ \\
\hline \multicolumn{7}{|c|}{3 Weeks of Storage } \\
\hline$\Delta E_{a b}^{*}$ & 10.0 & 17.2 & 20.6 & 3.8 & 6.0 & 6.7 \\
\hline$\Delta L^{*}$ & -8.7 & -11.7 & -14.2 & +1.9 & +2.3 & +2.4 \\
\hline$\Delta C^{*}{ }_{a b}$ & +4.4 & +7.3 & +13.3 & -2.7 & -5.7 & -6.3 \\
\hline$\Delta h_{a b}$ & $-3.8^{\circ}$ & $-4.7^{\circ}$ & $-10.0^{\circ}$ & $+0.1^{\circ}$ & $+1.6^{\circ}$ & $+2.1^{\circ}$ \\
\hline
\end{tabular}

${ }^{a} \mathrm{MC}, \mathrm{Mv} 3$-glc/ (+)-cat (200:200 mg/L); MC+Q50, MC+Q100, MC+Q200, MC solution $+50,+100,+200 \mathrm{mg} / \mathrm{L}$ of querc 3-glc. ${ }^{b} \mathrm{MQ}, \mathrm{Mv} 3-\mathrm{glc} /$ querc 3-glc (200:200 mg/L); MQ+C50, MQ+C100, MQ+C200, MQ solution +50,+100,+200 mg/L of (+)-cat.

limited. Similar results were obtained by Rustioni et al., ${ }^{17}$ who concluded that some flavonols are capable of displacing flavanols when they coexist in competitive equilibrium.

However, the opposite effect occurred when increasing concentrations of quercetin-3- $\beta$-D-glucoside were added to MC solutions. In this case, the initial copigmentation effect observed between malvidin-3-glucoside and (+)-catechin was comparatively weaker (note that the total color of MC was much lower than that of MQ). This fact probably favored the later interaction of the quercetin-3- $\beta$-D-glucoside with the anthocyanin chromophore, which gradually forced the global copigmentation equilibrium to a greater extent.

To establish whether the observed changes in the CIELAB parameters were visually relevant, color variations between binary and ternary copigmented solutions were calculated and expressed as colorimetric differences $\Delta E^{*}{ }_{a b}$ (see Table 2, data referred to $2 \mathrm{~h}$ ). Also, in an attempt of understand the significance of the color changes, the absolute lightness, chroma, and hue differences $\left(\Delta L^{*}, \Delta C^{*}{ }_{a b}\right.$, and $\left.\Delta h_{a b}\right)$ were calculated. According to Martinez et al., ${ }^{24} \Delta E^{*}{ }_{a b}$ around 3 units indicates, approximately, color differences appreciable to the human eye (as an average observer). On the basis of this premise, the most perceptible color changes were produced when quercetin-3- $\beta$ D-glucoside was added to the MC solutions. This color variation became more perceptible with higher concentrations of quercetin-3- $\beta$-D-glucoside, which was consistent with the effects observed in the total color and the magnitude of copigmentation. Specifically, the tendency was always toward higher decreases of $\Delta L^{*}$ and $\Delta h_{a b}$ (negative values), which correspond to visually increasing darkening and bluish effects. Simultaneously, chroma differences $\Delta C^{*}{ }_{a b}$ tended toward higher increases (positive values), resulting in more saturated solutions. Thus, it could be verified that in multiple copigmentation conditions quercetin-3- $\beta$-D-glucoside makes an important contribution to color intensity and tonality. In contrast, the color variations induced by $(+)$-catechin can be considered negligible at all of the concentrations tested as $\Delta E^{*}{ }_{a b}$ values in all color pairs were $<2$ units. Similarly, $\Delta L^{*}, \Delta C^{*}{ }_{a b}$, and $\Delta h_{a b}$ showed relatively minor changes. This fact confirms again the greater difficulty of $(+)$-catechin binding malvidin-3-glucoside in the presence of quercetin-3- $\beta$-D-glucoside.

Moreover, by comparing the relative contributions of lightness $\left(\% \Delta^{2} L\right)$, chroma $\left(\% \Delta^{2} C\right)$, and hue $\left(\% \Delta^{2} H\right)$ to each color difference $\left(\Delta E^{*}{ }_{a b}\right)$ it was possible to evaluate which color attribute was the most influenced (Figure 1). Taking into account only solutions with the largest perceptible color changes $(\mathrm{MC}+\mathrm{Q} 100$ and $\mathrm{MC}+\mathrm{Q} 200)$, it can be observed that quercetin3 - $\beta$-D-glucoside induced similar color effects independently of the concentration tested. Results showed that the lightness was the most overall influential parameter $\left(\% \Delta^{2} L \sim 50 \%\right)$, whereas the weights of the chroma and hue modifications were in general comparatively lower, but similar among them $\left(\% \Delta^{2} C\right.$ and $\% \Delta^{2} H$ $\sim 25 \%$ ).

Effect of Multiple Copigmentation on Color Stability by Differential Colorimetry. The evolution of the total color of solutions during the 3 weeks of storage in darkness at $25{ }^{\circ} \mathrm{C}$ is shown in Figure 2, where the mean value and standard deviation of samples are included. It can be observed that the addition of quercetin-3- $\beta$-D-glucoside is more effective in maintaining the total color of the MC solutions than the addition of $(+)$-catechin to the MQ solutions. As shown in Figure 2A, the Total color hardly decreased in MC binary solutions after 2 weeks of storage (around $28 \%$ ), whereas in the ternary solutions containing 50, 100, and $200 \mathrm{mg} / \mathrm{L}$ of quercetin$3-\beta$-D-glucoside the total color losses were $13.6,10.4$, and $4 \%$, respectively. Contrary to that, higher decreases of total color were observed in $\mathrm{MQ}+\mathrm{C}$ ternary solutions as the $(+)$-catechin ratio increased in the mixtures (Figure $2 \mathrm{~B}$ ).

The assessment of changes in the CIELAB parameters during storage was also decisive to establish the copigment having the greatest impact on the stability of the quantitative $\left(L^{*}\right.$ and $\left.C^{*}{ }_{a b}\right)$ or qualitative $\left(h_{a b}\right)$ color attributes (Figures 3 and 4 ). As can be observed, the chroma values decreased in all solutions over time while the hue values increased toward positive values. This means that the color variation that took place during stabilization in both binary and ternary mixtures was due to a decrease of the quantity of color and bluish hue $\left(h_{a b}\right.$ nearer to $0^{\circ}$, redness color)..$^{10}$

In particular, quercetin-3- $\beta$-D-glucoside was shown to better preserve the lightness than chroma and hue of $\mathrm{MC}+\mathrm{Q}$ ternary solutions (Figure 3). Independently of the concentration tested, the global variations of lightness values were always below $3.5 \%$ after 3 weeks of storage (Figure $3 \mathrm{~A}$ ). On the other hand, the evolution of chroma and hue (Figure 3B,C) suggests a greater stabilization effect at the highest concentration of quercetin-3- $\beta$-D-glucoside because the global losses of the quantity of color and bluish hues were less intense at $200 \mathrm{mg} / \mathrm{L}$. 


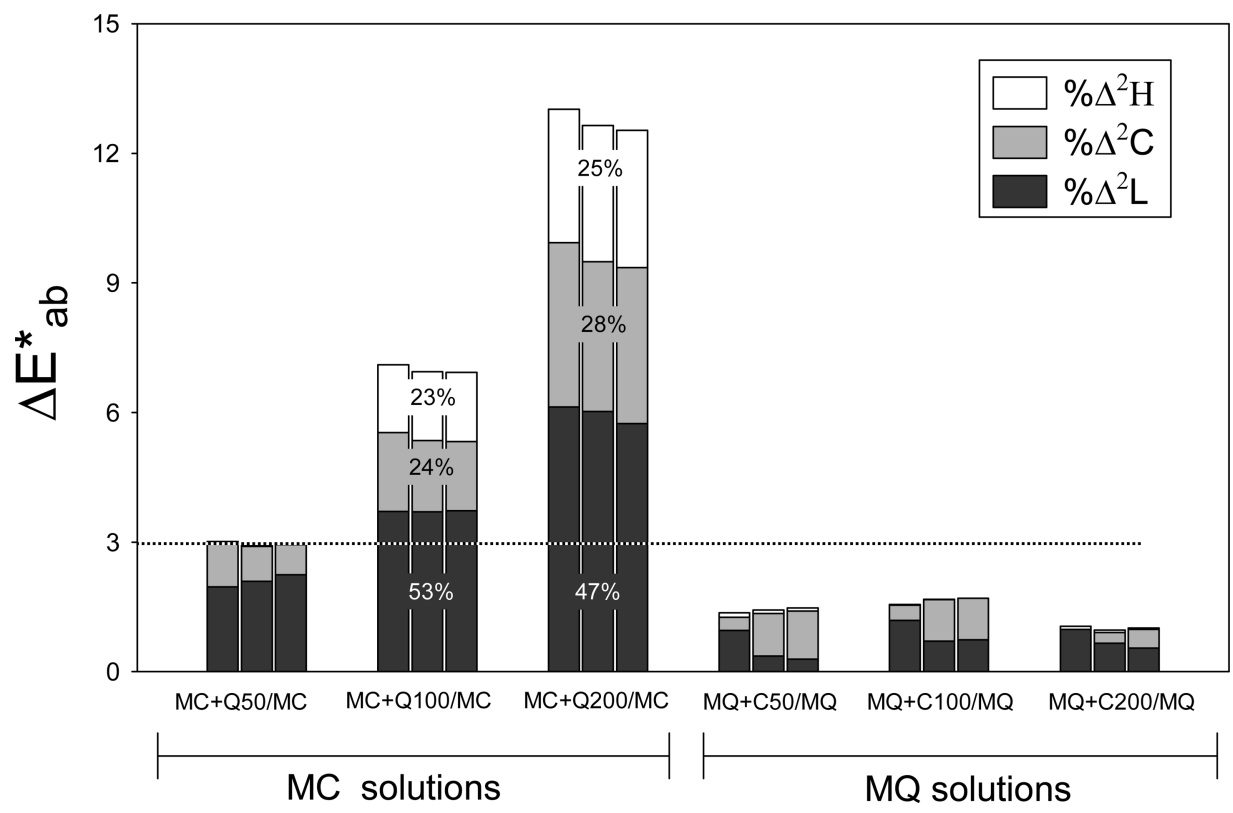

Figure 1. Color differences $\left(\Delta E^{*}{ }_{a b}\right)$, with the relative contribution of lightness, chroma, and hue $\left(\% \Delta^{2} L, \% \Delta^{2} C, \% \Delta^{2} H\right)$, between binary and ternary copigmented solutions after the addition of increasing concentrations of quercetin-3- $\beta$-O-glucoside to MC solution and (+)-catechin to MQ solutions, calculated at $2 \mathrm{~h}\left(25^{\circ} \mathrm{C}\right)$.

A)

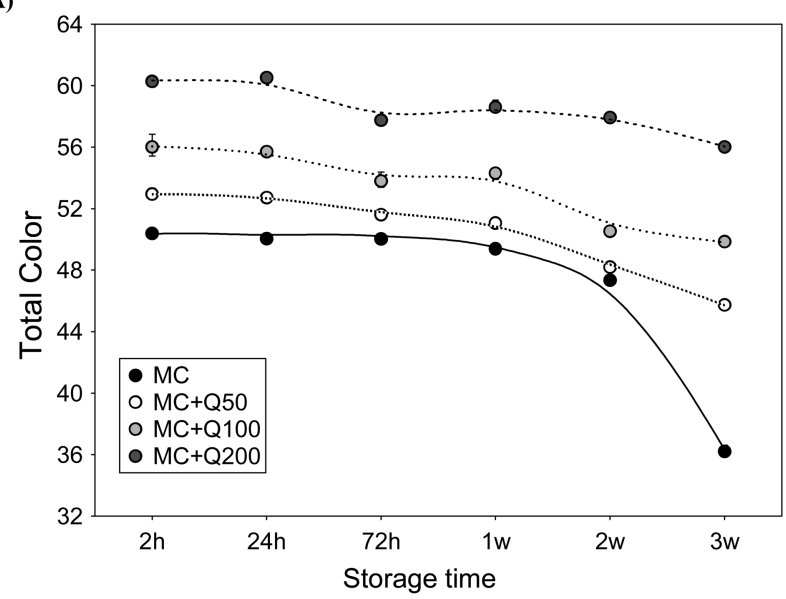

B)

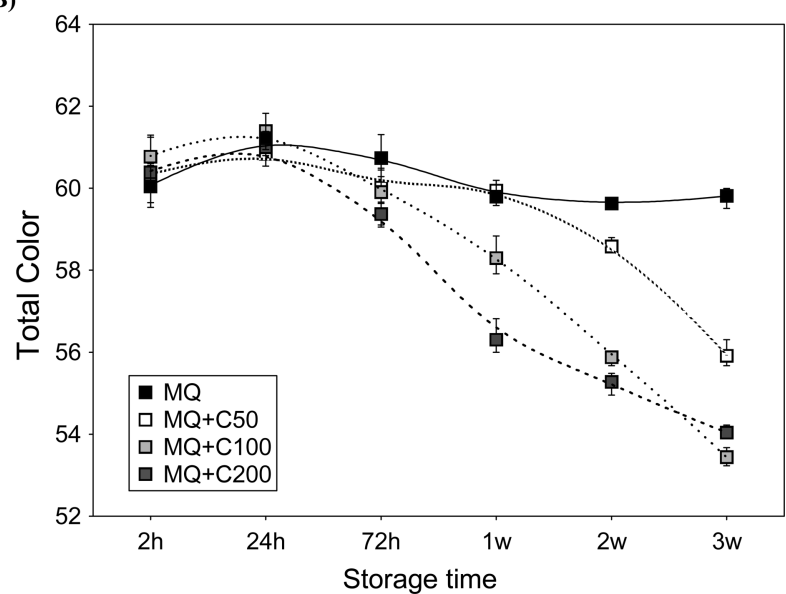

Figure 2. Influence of increasing concentrations of quercetin-3- $\beta-O$ glucoside and $(+)$-catechin on the evolution of the total color of MC and MQ binary and ternary solutions, respectively, over the storage period at $25^{\circ} \mathrm{C}$ : (A) MC solutions; (B) MQ solutions.
(+)-Catechin showed a lower protective effect on the quantitative attributes of color, especially for chroma variations (Figure 4A,B). During storage, the chroma values notably decreased about $13 \%$ with concentrations of $(+)$-catechin up to $100 \mathrm{mg} / \mathrm{L}$. Thus, surprisingly, the binary solution MQ showed greater color stability over time than in the presence of increasing concentrations of $(+)$-catechin. These results highlight that adding copigments does not always lead to a stabilizing effect, but depends on the type of copigments as well as on its concentration.

Furthermore, the assessment of the color differences $\left(\Delta E^{*}{ }_{a b}\right)$ occurring at 24 and $72 \mathrm{~h}$ and at 1,2 , and 3 weeks, in relation to samples taken at $2 \mathrm{~h}$, provides an objective evaluation of the chromatic stability for each solution over time (Figure 5). The lower values of $\Delta E^{*}{ }_{a b}$ during storage in $\mathrm{MC}+\mathrm{Q}$ ternary solutions than in $\mathrm{MC}$ binary solutions indicate lower color variation and, thus, higher color stability (Figure 5A). Considering the whole period of storage, the lowest color differences corresponded to $\mathrm{MC}+\mathrm{Q} 200$ and $\mathrm{MC}+\mathrm{Q} 100$ solutions compared to $\mathrm{MC}+\mathrm{Q} 50$ and $\mathrm{MC}\left(\Delta E^{*}{ }_{a b}=9.8,10.5,12.1\right.$, and 16.4, respectively). In contrast, growing $\Delta E^{*}{ }_{a b}$ values in $\mathrm{MQ}+\mathrm{C}$ ternary solutions relative to those in MQ binary solution indicate higher color variation and, thus, lower color stability (Figure 5B). Nevertheless, this negative effect seemed to greatly depend on the $(+)$-catechin concentration in the mixtures. It can be observed that the color modification experienced by $\mathrm{MQ}+\mathrm{C} 50$ solution was not easily detectable $\left(\Delta E^{*}{ }_{a b}<3\right)^{24}$ until the end of the storage period. This means that $(+)$-catechin does not cause important color destabilization in multiple conditions at low concentrations ( $50 \mathrm{mg} / \mathrm{L}$ in our conditions). However, at (+)-catechin concentrations up to $100 \mathrm{mg} / \mathrm{L}$, $\Delta E^{*}{ }_{a b}$ values were detectable from the first weeks of storage.

As a consequence of the different color stabilities over time, $\mathrm{MC}+\mathrm{Q}$ and $\mathrm{MQ}+\mathrm{C}$ ternary solutions could be differentiated at the end of storage period in terms of luminosity, intensity, and chromaticity from their respective $\mathrm{MC}$ and $\mathrm{MQ}$ binary solutions (Table 1). Specifically, MC+Q solutions showed 
A)

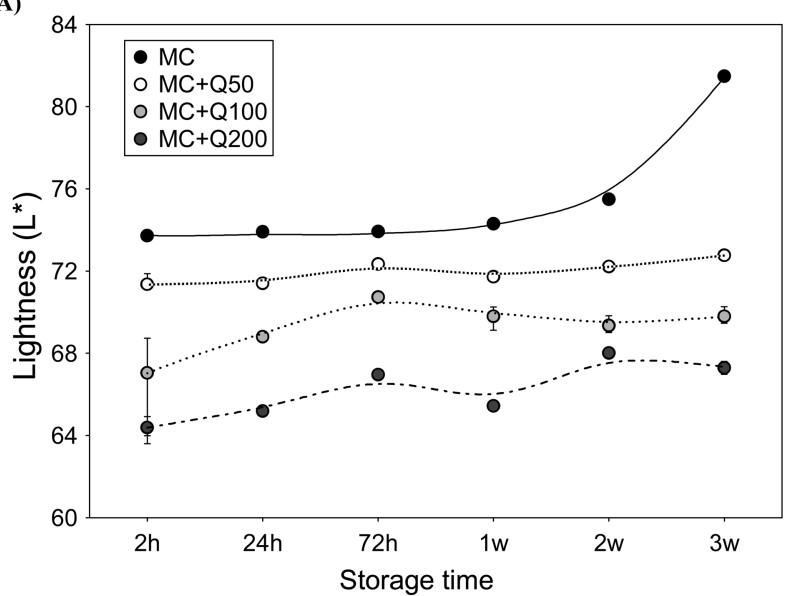

B)

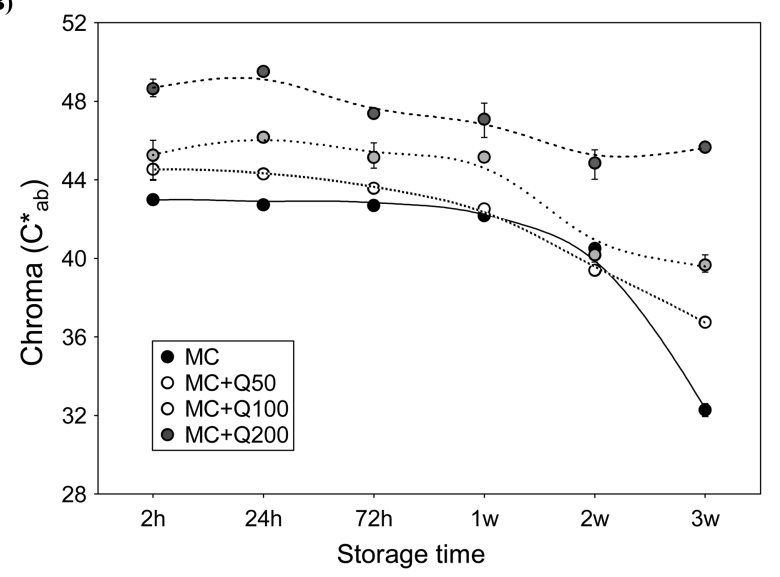

C)

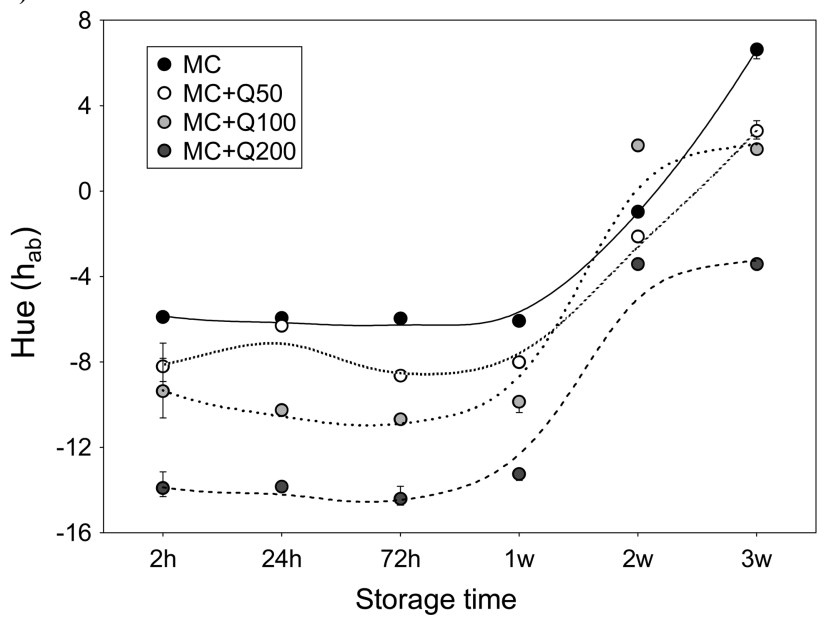

Figure 3. Influence of increasing concentrations of quercetin-3- $\beta-O$ glucoside on the evolution of the CIELAB colorimetric parameters of $\mathrm{MC}$ binary and ternary solution over the storage period at $25{ }^{\circ} \mathrm{C}$ in darkness: (A) lightness, $L^{*}$; (B) chroma, $C^{*} a b$; (C) hue, $h_{a b}$.

significantly lower values of $L^{*}$ and hue but higher values of total color and $C^{*}{ }_{a b}$ than MC solution. In terms of detectable color variations $^{24}$ (Table 2), the highest color difference value was obtained between $\mathrm{MC}$ and $\mathrm{MC}+\mathrm{Q} 200$ solutions $\left(\Delta E^{*}{ }_{a b}=\right.$ 20.6). The negative values of lightness and hue differences found among them $\left(\Delta L^{*}=-14.2, \Delta h_{a b}=-10.0^{\circ}\right)$, but positive chroma difference $\left(\Delta C^{*}{ }_{a b}=+13.3\right)$, means that $\mathrm{MC}$ + Q200 solutions had darker and more intense color with more bluish hue than MC solutions.

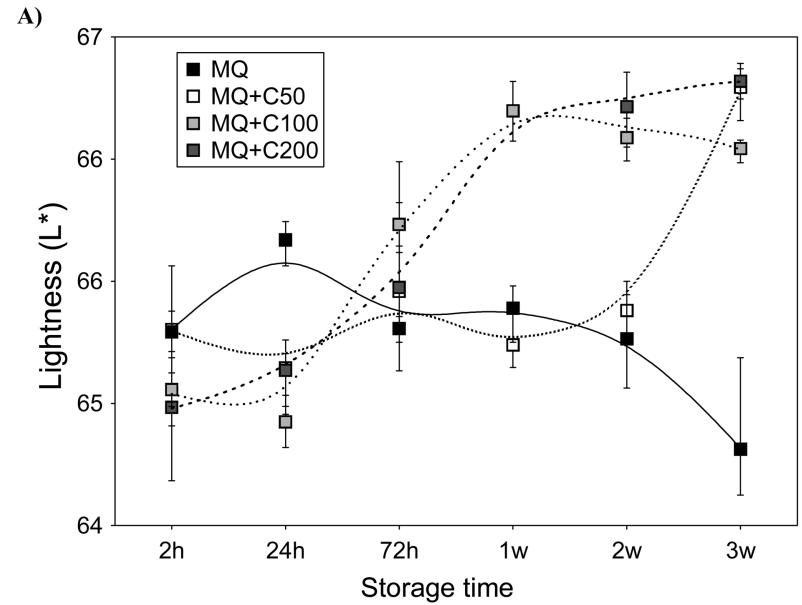

B)
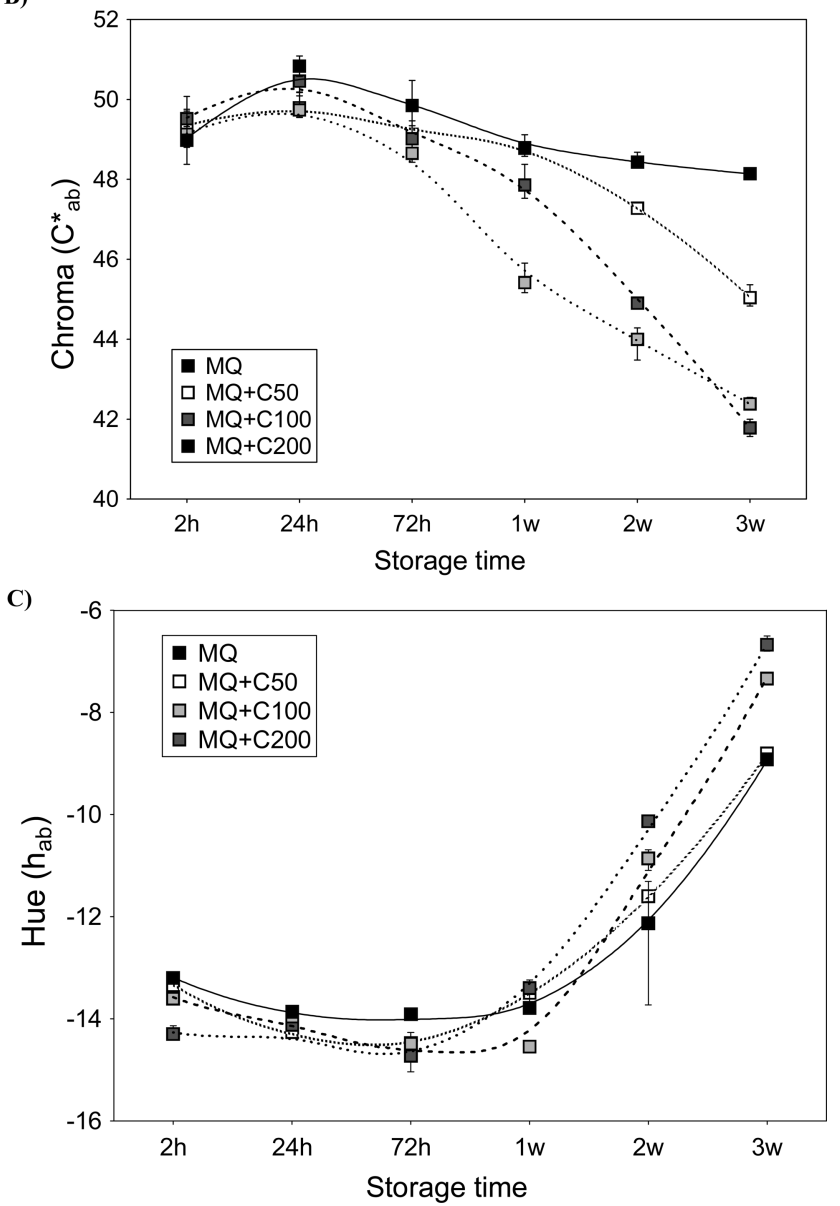

Figure 4. Influence of increasing concentrations of $(+)$-catechin on the evolution of the CIELAB colorimetric parameters of MQ binary and ternary solution over the storage period at $25{ }^{\circ} \mathrm{C}$ in darkness: (A) lightness, $L^{*}$; (B) chroma, $C^{*}{ }_{a b}$; (C) hue, $h_{a b}$.

On the other hand, $\mathrm{MQ}+\mathrm{C}$ solutions showed significantly higher values of $L^{*}$ but lower total color and $C^{*}{ }_{a b}$ than MQ solutions (Table 1). In this case, the trend of the lightness and chroma differences among pairs of solutions was the opposite. Positive values for $\Delta L^{*}$ and negative values for $\Delta C^{*}{ }_{a b}$ indicate that the final color of $\mathrm{MQ}+\mathrm{C}$ solutions was lighter and less saturated than that of MQ solution. Again, the color differences were most appreciable with the highest concentration of (+)-catechin (MC+Q100 and MC+Q200 solutions). 

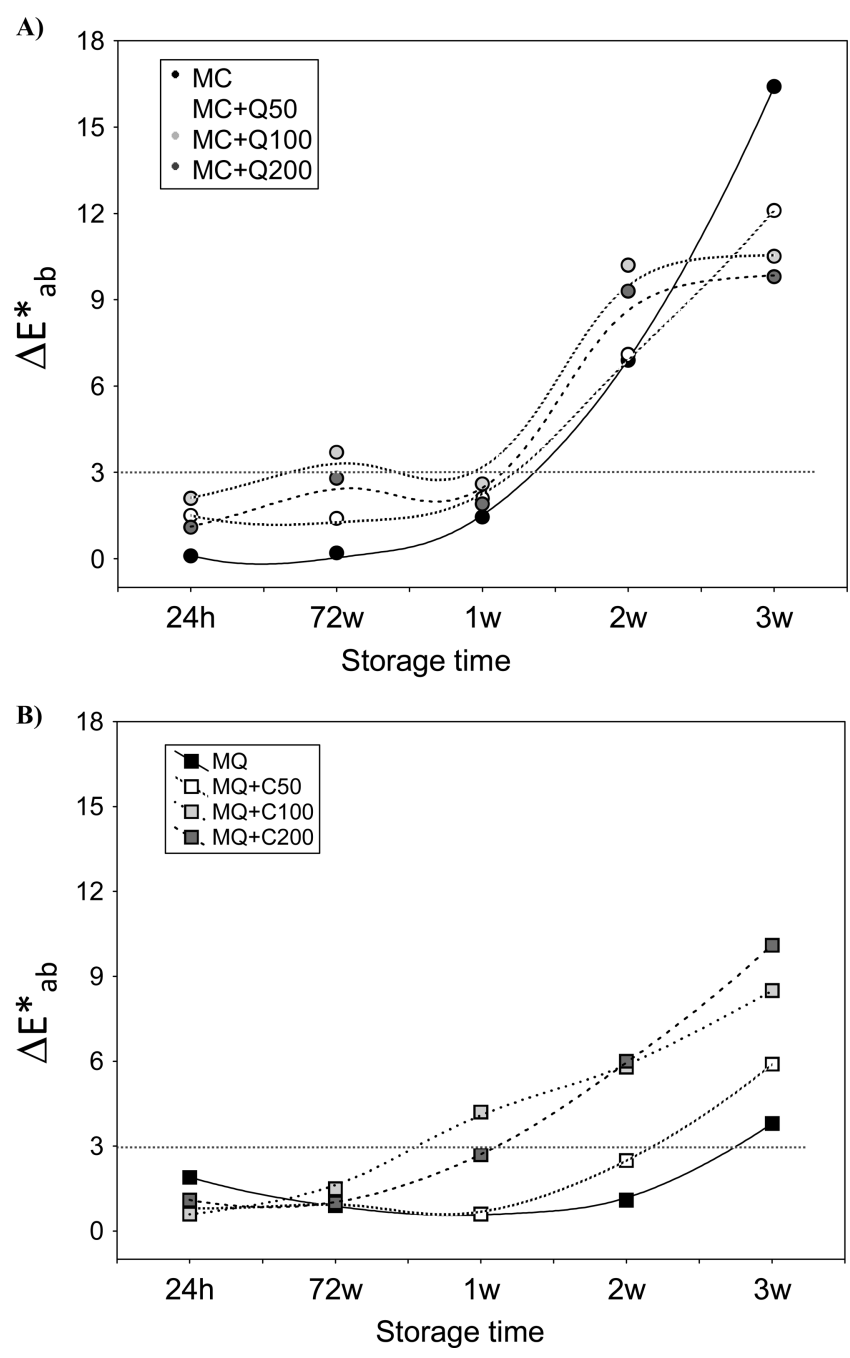

Figure 5. Influence of increasing concentrations of quercetin-3- $\beta$-Oglucoside and $(+)$-catechin on the color variation $\left(\Delta E^{*}{ }_{a b}\right)$ of $\mathrm{MC}$ and MQ binary and ternary solutions, respectively, over the storage period at $25{ }^{\circ} \mathrm{C}$ : (A) MC solutions; (B) MQ solutions.

Thus, with the whole set of data taken into account, it was confirmed that the addition of increasing amounts of quercetin$3-\beta$-D-glucoside to $\mathrm{MC}$ binary mixtures led to $\mathrm{MC}+\mathrm{Q}$ ternary solutions with more stable color that kept their intensity and vivid bluish tonalities for a longer time, which represent color characteristics highly appreciated in young red wines. In contrast, the addition of increasing amounts of $(+)$-catechin to MQ binary mixtures led to $\mathrm{MQ}+\mathrm{C}$ ternary solutions with less stable color that maintain their vivid red intensity for only a short time, so their value as potential additives in the wine industry could be rather questionable because the minimization of color fluctuation is essential to maintain the global quality of wines.

Effect of Multiple Copigmentation Interactions on Chemical Stability. Figure 6 shows the changes in the concentration of malvidin-3-glucoside $(\mathrm{mg} / \mathrm{L} \pm \mathrm{SD})$ in solutions over time. Although the presence of the copigments does not impede the loss of the anthocyanin content, the protective effects of quercetin-3- $\beta$-D-glucoside and $(+)$-catechin in multiple conditions were quite different. As observed in Figure 6A, the content of malvidin-3-glucoside in $\mathrm{MC}$ and $\mathrm{MC}+\mathrm{Q}$ solutions is maintained more or less constant during the first 2 weeks of storage. After this, the amount of malvidin-3glucoside declines dramatically, the rate of degradation being
A)

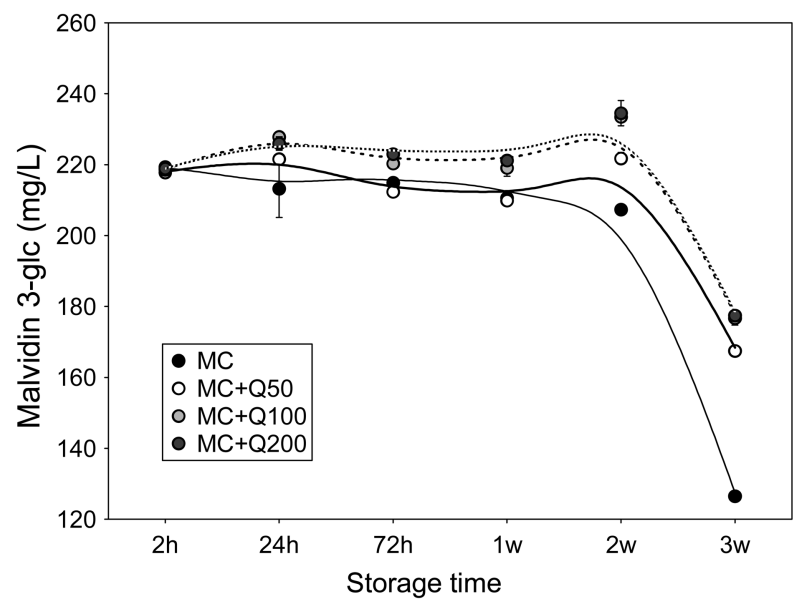

B)

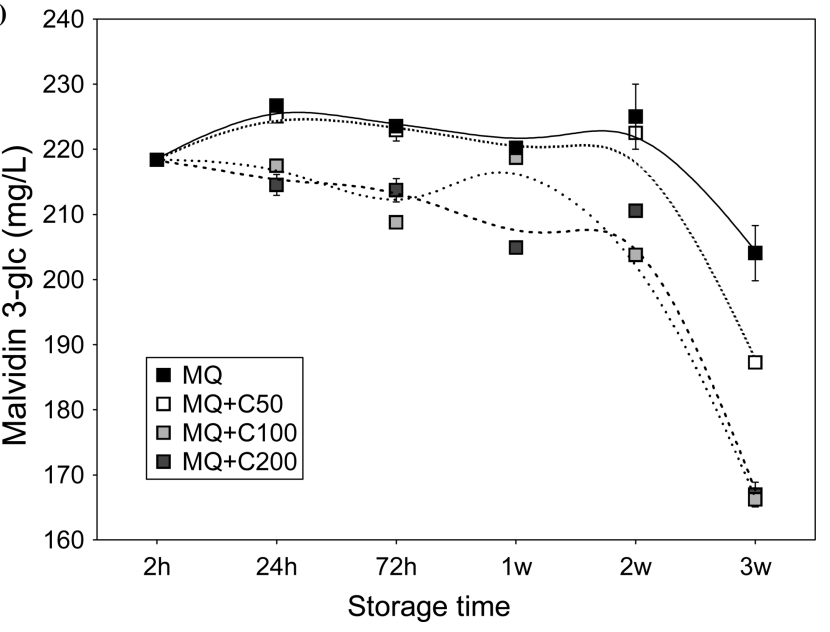

Figure 6. Influence of increasing concentrations of quercetin-3- $\beta-O-$ glucoside and (+)-catechin on the evolution of the malvidin-3glucoside content of MC and MQ binary and ternary solutions, respectively, over the storage period at $25^{\circ} \mathrm{C}$ : (A) MC solutions; (B) MQ solutions.

less intense in the presence of quercetin-3- $\beta$-D-glucoside. The global content of malvidin-3-glucoside decreased over the whole storage period by $42 \%$ in MC binary solutions. In comparison, the anthocyanin degradation was notably reduced to $24,19.5$, and $19 \%$ with the addition of 50,100 , and $200 \mathrm{mg} / \mathrm{L}$ of quercetin-3- $\beta$-D-glucoside, respectively. These observations confirm that quercetin-3- $\beta$-D-glucoside behaved as a protective copigment in multiple conditions by preventing excessive pigment loss. In general terms, the higher the concentration of quercetin-3- $\beta$-D-glucoside in MC solution, the greater protective effects against anthocyanin degradation, which was in accordance with the amplitude of the effects observed in color stability. Nevertheless, the positive effect of quercetin-3- $\beta$-Dglucoside cannot be raised to an unlimited extent because no further improvement in the anthocyanin stability was produced when its concentration exceeded a certain level (in our conditions, up to $100 \mathrm{mg} / \mathrm{L}$ ). This observation was in agreement with previous studies. ${ }^{2,32}$ The analysis of variance (ANOVA, Tukey test) revealed significant differences $(p<0.05)$ for the final levels of malvidin-3-glucoside between $\mathrm{MC}$ and $\mathrm{MC}+\mathrm{Q}$ solutions. MC solution showed the lowest content in malvidin3-glucoside $(126.5 \pm 0.2 \mathrm{mg} / \mathrm{L})$. As expected, no statistically significant differences were found for the anthocyanin content between $\mathrm{MC}+\mathrm{Q} 100$ and $\mathrm{MC}+\mathrm{Q} 200$ solutions (176.7 \pm 2.8 and 
$177.5 \pm 0.3 \mathrm{mg} / \mathrm{L}$, respectively) because the losses of malvidin3 -glucoside were very similar in both ternary solutions. Thus, the application of quercetin-3- $\beta$-D-glucoside as wine copigments appears to be promising because it tends to significantly improve the stability of the anthocyanins in multiple conditions over time.

On the other hand, the anthocyanin stability of MQ and $\mathrm{MQ}+\mathrm{C}$ solutions during storage is presented in Figure 6B. It can be observed that the malvidin-3-glucoside degradation occurred more rapidly in the presence of $(+)$-catechin $(\mathrm{MQ}+\mathrm{C}$ solutions), which is in accordance with the color evolution. In particular, more remarkable losses occurred from the earliest moment of storage at concentrations of $(+)$-catechin up to $100 \mathrm{mg} / \mathrm{L}$ (approximately by $24 \%$ ). After 3 weeks of storage, significantly $(p<0.05)$ higher contents of malvidin-3-glucoside were found in MQ and MQ+C50 solutions (204.8 \pm 5.9 and $187.3 \pm 0.3 \mathrm{mg} / \mathrm{L}$, respectively), whereas this value fell to $166.1 \pm 1.2$ and $166.9 \pm 2.7 \mathrm{mg} / \mathrm{L}$ in $\mathrm{MQ}+\mathrm{C} 100$ and $\mathrm{MQ}+\mathrm{C} 200$ solutions. This fact seems to indicate that, at high concentrations, $(+)$-catechin can interfere with the existing malvidin-3-glucoside/ quercetin-3- $\beta$-D-glucoside equilibrium, diminishing their chemical stability. This antagonistic effect, clearly potentiated with time in our conditions, was also observed by Rustioni et al., ${ }^{17}$ who demonstrated that certain combinations of copigments (especially those from seeds, as could be (+)-catechin) can negatively affect the global copigmentation equilibrium by breaking tanninanthocyanin interactions.

In summary, this work has shown that quercetin-3- $\beta$-Dglucoside and $(+)$-catechin exhibit quite different abilities to interact with malvidin-3-glucoside in ternary mixtures depending on their specific binding strength and concentration, which have important consequences on the color and chemical stability during storage. Differential colorimetry has demonstrated the fundamental role of quercetin-3- $\beta$-D-glucoside as a potential wine additive due to its immediate copigmentation effect in multiple systems and higher potential for stabilization over time. Our findings also showed the greater difficulty of $(+)$-catechin binding to malvidin-3-glucoside in the presence of quercetin-3- $\beta$ D-glucoside and its lower potential to lead to chemical and colorimetric stabilization. It should be borne in mind, therefore, that certain flavonoid combinations do not always result in positive effects on color by multiple copigmentation but also could cause negative effects. In this sense, further studies need to be done to better understand the mechanisms involved in the anthocyanin-flavanol-flavonol multiple interactions under different conditions ( $\mathrm{pH}$, temperature, sulfites, etc.) as well as to strategically select appropriate flavonoid combinations that promote synergistic interactions and avoid antagonisms.

\section{ASSOCIATED CONTENT}

\section{S Supporting Information}

Chemical structures of the pigment and copigments used and visible absorbance spectra of the solutions prepared for this study. This material is available free of charge via the Internet at http://pubs.acs.org.

\section{AUTHOR INFORMATION}

\section{Corresponding Author}

*(M.T.E.-B.) Phone: +34 923 294537. Fax: +34 923294515.

E-mail: escriban@usal.es.

\section{Funding}

This research was financially supported by the Spanish MICINN (Project ref AGL2011-30254-C02-01) and (Project ref
AGL2011-30254-C02-02) and Consejería de Economía, Innovación, Ciencia y Empleo, Junta de Andalucía, Spain (Project P11-AGR-7843). F.J.R.-P. thanks VPPI-Universidad de Sevilla for a postdoctoral grant.

\section{Notes}

The authors declare no competing financial interest.

\section{ACKNOWLEDGMENTS}

We are indebted to Dr. Modesto Carballo (Biology Service, CITIUS, Universidad de Sevilla) for technical assistance.

\section{REFERENCES}

(1) Monagas, M.; Bartolome, B.; Gomez-Cordoves, C. Updated knowledge about the presence of phenolic compounds in wine. Crit. Rev. Food Sci. Nutr. 2005, 45, 85-118.

(2) Eiro, M. J.; Heinonen, M. Anthocyanin color behavior and stability during storage: effect of intermolecular copigmentation. J. Agric. Food Chem. 2002, 50, 7461-7466.

(3) Shikov, V.; Kammerer, D. R.; Mihalev, K.; Mollov, P.; Carle, R. Heat stability of strawberry anthocyanins in model solutions containing natural copigments extracted from rose (Rosa damascena Mill.) petals. J. Agric. Food Chem. 2008, 56, 8521-8526.

(4) Boulton, R. The copigmentation of anthocyanins and its role in the color of red wine: a critical review. Am. J. Enol. Vitic. 2001, 52, 6787.

(5) Castañeda-Ovando, A.; Pacheco-Hernández, M.; PáezHernández, M.; Rodríguez, J. A.; Galán-Vidal, C. A. Chemical studies of anthocyanins: a review. Food Chem. 2009, 113, 859-871.

(6) Bakker, J.; Timberlake, C. F. Isolation, identification, and characterization of new color-stable anthocyanins occurring in some red wines. J. Agric. Food Chem. 1997, 45, 35-43.

(7) De Freitas, V.; Mateus, N. Chapter 3. Updating wine pigments. In Recent Advances in Polyphenol Research; Santos-Buelga, C., EscribanoBailon, M. T., Lattanzio, V., Eds.; Wiley-Blackwell: Oxford, UK, 2010; Vol. 2.

(8) Schwarz, M.; Picazo-Bacete, J. J.; Winterhalter, P.; HermosínGutiérrez, I. Effect of copigments and grape cultivar on the color of red wines fermented after the addition of copigments. J. Agric. Food Chem. 2005, 53, 8372-8381.

(9) García-Marino, M.; Escudero-Gilete, M. L.; Heredia, F. J.; Escribano-Bailón, M. T.; Rivas-Gonzalo, J. C. Color-copigmentation study by tristimulus colorimetry (CIELAB) in red wines obtained from Tempranillo and Graciano varieties. Food Res. Int. 2013, 51, 123-131.

(10) Gordillo, B.; Cejudo-Bastante, M. J.; Rodríguez-Pulido, F. J.; Jara-Palacios, M. J.; Ramírez-Pérez, P.; González-Miret, M. L.; Heredia, F. J. Impact of adding white pomace to red grapes on the phenolic composition and color stability of syrah wines from a warm climate. $J$. Agric. Food Chem. 2014, 62, 2663-2671.

(11) García-Marino, M.; Hernández-Hierro, J. M.; Rivas-Gonzalo, J. C.; Escribano-Bailón, M. T. Colour and pigment composition of red wines obtained from co-maceration of Tempranillo and Graciano varieties. Anal. Chim. Acta 2010, 660, 134-142.

(12) Cavalcanti, R. N.; Santos, D. T.; Meireles, M. A. A. Non-thermal stabilization mechanisms of anthocyanins in model and food systems - an overview. Food Res. Int. 2011, 44, 499-509.

(13) Baranac, J. M.; Petranovic, N. A.; Dimitric-Markovic, J. M. Spectrophotometric study of anthocyan copigmentation reactions. 2. Malvin and the nonglycosidized flavone quercetin. J. Agric. Food Chem. 1997, 45, 1694-1697.

(14) Berké, B.; De Freitas, V. A colorimetric study of oenin copigmented by procyanidins. J. Sci. Food Agric. 2007, 87, 260-265.

(15) Gordillo, B.; Rodríguez-Pulido, F. J.; Escudero-Gilete, M. L.; González Miret, M. L.; Heredia, F. J. Comprehensive colorimetric study of anthocyanic copigmentation in model solutions. Effects of $\mathrm{pH}$ and molar ratio. J. Agric. Food Chem. 2012, 60, 2896-2905. 
(16) Teixeira, N.; Cruz, L.; Brás, N. F.; Mateus, N.; Ramos, M. J.; De Freitas, V. Structural features of copigmentation of oenin with different polyphenol copigments. J. Agric. Food Chem. 2013, 61, 6942-6948.

(17) Rustioni, L.; Bedgood, D. R.; Failla, O.; Prenzler, P. D.; Robards, $\mathrm{K}$. Copigmentation and anti-copigmentation in grape extracts studied by spectrophotometry and post-column-reaction HPLC. Food Chem. 2012, 132, 2194-2201.

(18) Pinelo, M.; Manzocco, L.; Nuñez, M. J.; Nicoli, M. C. Interaction among phenols in food fortification: negative synergism on antioxidant capacity. J. Agric. Food Chem. 2004, 52, 1177-1180.

(19) Hidalgo, M.; Sánchez-Moreno, C.; Pascual-Teresa, S. Flavonoidflavonoid interaction and its effect on their antioxidant activity. Food Chem. 2010, 121, 691-696.

(20) Ioannou, I.; Hafsa, I.; Salem Hamdi, S.; Charbonnel, C.; Ghoul, M. Review of the effects of food processing and formulation on flavonol and anthocyanin behaviour. J. Food Eng. 2012, 111, 208-217.

(21) González-Manzano, S.; Dueñas, M.; Rivas-Gonzalo, J. C.; Escribano-Bailón, M. T.; Santos-Buelga, C. Studies on the copigmentation between anthocyanins and flavan-3-ols and their influence in the colour expression of red wine. Food Chem. 2009, 114, 649-656.

(22) Jara-Palacios, M. J.; Gordillo, B.; González-Miret, M. L.; Hernanz, D.; Escudero-Gilete, M. L.; Heredia, F. J. Comparative study of the enological potential of different winemaking byproducts: implications in the antioxidant activity and color expression of red wine anthocyanins in a model solution. J. Agric. Food Chem. 2014, 62, 6975-6983.

(23) Liu, H.; Chen, Y.; Hao, Y.; Zheng, N.; Jia, A. The evaluation of lightness and chroma difference for images according to color difference formulae. Appl. Mech. Mater. 2012, 130, 3036-3040.

(24) Martínez, J. A.; Melgosa, M.; Pérez, M. M.; Hita, E.; Negueruela, A. I. Note. Visual and instrumental color evaluation in red wines. Food Sci. Technol. Int. 2001, 7, 439-444.

(25) Cejudo-Bastante, M. J.; Gordillo, B.; Hernanz, D.; EscuderoGilete, M. L.; González-Miret, M. L.; Francisco J. Heredia, F. J. Effect of the time of cold maceration on the evolution of phenolic compounds and colour of Syrah wines elaborated in warm climate. Int. J. Food Sci. Technol. 2014, 49, 1886-1892.

(26) Gonnet, J. Colour effects of co-pigmentation of anthocyanin revisited - 3. A further description using CIELAB differences and assessment of matched colours using the CMC model. Food Chem. 2001, 75, 473-485.

(27) Gordillo, B.; López-Infante, M. I.; Ramírez-Pérez, P.; GonzálezMiret, M. L.; Heredia, F. J. Influence of prefermentative cold maceration on the color and anthocyanic copigmentation of organic Tempranillo wines elaborated in a warm climate. J. Agric. Food Chem. 2010, 58, 6797-6803.

(28) Heredia, F. J.; Álvarez, C.; González-Miret, M. L.; Ramírez, A. CromaLab, análisis de color. Registro General de la Propiedad Intelectual, 2004.

(29) CIE. Technical Report Colorimetry; Commission Internationale de l'Eclairage Central Bureau: Vienna, Austria, 2004.

(30) StatSoft Inc. STATISTICA (data analysis software system), v 8; StatSoft Inc.: Tulsa, OK, USA, 2007.

(31) Gómez-Míguez, M.; Gonzalez-Manzano, S.; González-Miret, M. L.; Escribano-Bailón, M. T.; Heredia, F. J.; Santos-Buelga, C. Influence of different phenolic copigments on the color of malvidin 3-glucoside. J. Agric. Food Chem. 2006, 54, 5422-5429.

(32) Sun, J.; Cao, X.; Bai, W.; Liao, X.; Hua, X. Comparative analyses of copigmentation of cyanidin 3-glucoside and cyanidin 3-sophoroside from red raspberry fruits. Food Chem. 2010, 120, 1131-1137. 